\title{
El Museo de Arte Moderno de Bogotá. El Mambo, una singular experiencia
}

Kelly Carpio Ochoa

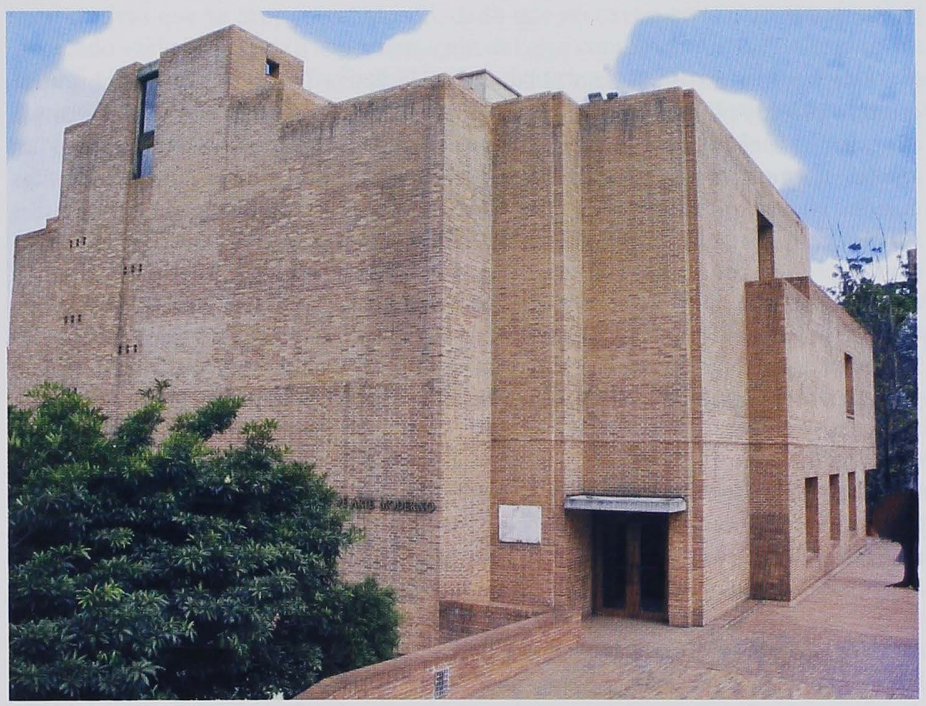

\section{HISTORIA}

La historia del MAMBO (Museo de Arte Moderno de Bogotá), según Gloria Zea, su actual directora, ha estado estrechamente vinculada con la realidad del país, con sus posibilidades económicas y sus necesidades estéticas. Su colección y su actual sede son el resultado de un esfuerzo colectivo en el que han participado distintos estamentos de la sociedad colombiana: el gobierno, la empresa privada, la banca, los artistas e intelectuales, los periodistas y el público; lo que permite afirmar que se trata de "una expresión singular" de la cultura colombiana.

Hacia 1950 existía en amplios sectores de la sociedad colombiana la conciencia de la 
necesidad de crear una institución que conservara y difundiera las obras más significativas de sus artistas, forjando así una historia respaldada con ejemplos que ilustraran sus aportes y su evolución. Dicha iniciativa fue tomada por el Ministro de Educación Aurelio Caycedo quien, por Decreto $N^{\circ} 2057$ del 27 de julio de 1955, fundó el Museo de Arte Moderno de Bogotá como una entidad para el desarrollo cultural y artístico del país.

Durante los primeros años de existencia como entidad sin sede, funcionó en la oficina de su primer director, el arquitecto Gabriel Serrano Camargo, en el centro de Bogotá. Allí se reunía la Junta Directiva que redactó los primeros estatutos de la institución definiendo al museo como una "Corporación autónoma”. La Junta Directiva solicitó la revocación de su carácter oficial y, mediante el Decreto $\mathrm{N}^{\circ} 150$ de mayo de 1958 , quedó en libertad de buscar su propia financiación con la empresa privada, adquiriendo así una independencia que ha sido fundamental para su estabilidad institucional.

El 31 de octubre de 1963, bajo el liderazgo de Marta Traba, el MAMBO abrió por primera vez sus puertas al público, en una sede ubicada en la Carrera 7a., con la exposición Tumbas de Juan Antonio Roda. Bajo su dirección el Museo tuvo un ambicioso programa de actividades: conferencias, charlas de los pintores y visitas guiadas en sus muestras. Luego, en 1956, se trasladó al edificio de Bellas Artes situado en la Ciudad Universitaria, donde se realizaron algunas exposiciones, entre ellas la primera muestra de su colección permanente, que hasta entonces contaba con 65 obras entre pinturas, dibujos y grabados. En 1969 la Junta Directiva designa a Gloria Zea para la dirección del Museo, quien consigue un nuevo local en el Edificio Bavaria; éste fue inaugurado el 29 de octubre de 1970 con una exposición organizada por el Consejo Internacional de Arte Moderno de Nueva York, Móviles y Estábiles de Alexander Calder.

En 1971, el Distrito Especial cedió al museo los espacios disponibles del Planetario Distrital, su cuarta sede provisional, que se inauguró el 21 de julio de ese año. Allí se realizaron exposiciones de gran interés histórico como: El arte del surrealismo, Color; Miró: cincuenta grabados; Picasso: maestro del grabado; y París y el arte contemporáneo.

En 1974, después de un largo trámite, se consigue finalmente que la Dirección de Inmuebles Nacionales cediera para su construcción los terrenos que eran propiedad de la Nación, a continuación de la Biblioteca Nacional. El proyecto para la construcción de una sede propia se inició bajo la responsabilidad del Arquitecto Rogelio Saltona. La obra concluida se inauguró el 25 de abril de 1979 con una muestra colectiva de pinturas y esculturas de la colección permanente.

La principal tarea del Museo fue siempre la difusión y estímulo del arte colombiano, llevada a cabo por muestras retrospectivas como las de los maestros Alejandro Obregón, Edgar Negret, Enrique Grau, Eduardo Ramírez y Hernando Lemaitre, así como grandes exposiciones del trabajo reciente de Manuel Hernández, Olga de Amaral, Antonio Roda, Feliza Burstyn, Carlos Rojas, Carlos Granada, Luis Caballero, Ana Mercedes Hoyos, Omar Rayo, Beatriz González, Leonel Góngora entre otros. 
exclusivamente por donaciones de artistas. Esta colección está conformada por pinturas, esculturas, grabados, diseños gráficos y ensamblajes, los cuales pueden ilustrar, a través de destacados ejemplos, no sólo la evolución del arte colombiano desde 1856 (desde el desarrollo de la Escuela Nacional de Bellas Artes), sino también el desarrollo internacional de los distintos estilos que caracterizan el arte del siglo XX. También cuenta con una colección fotográfica de 6,000 piezas, resultado de la exposición: La historia de la fotografia en Colombia; más 44,654 piezas que constituyen el legado del reconocido fotógrafo bogotano Juan Nepomuceno Gómez, donado a la entidad por el Banco de la República.

El Museo de Arte Moderno de Bogotá, fundación privada sin fines de lucro, se ha trazado una nueva meta: construir un edificio aledaño que permita presentar la colección permanente sin tener que suspender el programa de exposiciones temporales, ampliación necesaria porque su actual edificio no permite colmar las expectativas que se propone el Museo, dado que no existe en la ciudad un espacio dedicado exclusivamente a la presentación del arte contemporáneo. "De esta forma tendrá el público del país la posibilidad de recurrir en todo momento al estímulo espiritual que representa la apreciación de los logros artísticos alcanzados en su propio entorno, y a las múltiples enseñanzas que ellos entrañan"1.

\section{CARACTERÍSTICAS}

El MAMBO ocupa su actual sede desde 1979. Tiene 5,000 metros cuadrados de amplitud divididos en cuatro pisos, un patio de esculturas, una fototeca, un auditorio, una sala de cine, una biblioteca especializada, un almacén y un restaurante. En sus instalaciones se ofrecen los servicios de la biblioteca especializada en artes visuales contemporáneas que cuenta con más de 4,500 volúmenes y la fototeca, que reúne más de 100,000 fotografías y negativos procedentes de tres archivos fotográficos ("Artes plásticas contemporáneas", "La historia de la Fotografía en Colombia", y el archivo J.N. Gómez, que contiene 33,000 placas originales de este retratista bogotano de comienzos de siglo XX).

Presenta constantemente durante todo el año y de forma rotativa exposiciones de arte moderno y contemporáneo de artistas nacionales y extranjeros. La colección privada del Museo comprende obras de artistas como Botero, Manssur, Grau, Villamizar, Negret, Álvaro Barrios, Ana Mercedes Hoyos y María de la Paz Jaramillo.

Tiene servicios complementarios: talleres, cursos para guías, visitas guiadas en lengua extranjera, ciclos de cine, cursos de apreciación y análisis de cine y conferencias diversas. Actualmente promueve la Bienal de Arte de Bogotá.

\section{SEDE}

El MAMBO fue un proyecto del destacado Arq. Rogelio Salmona. Es un edificio de cuatro pisos unidos por una escalera central, cuyo recorrido es laberíntico. Esta

ZEA, Gloria. El Museo de Arte Moderno de Bogotá. Una experiencia singular. Bogotá, El Sello editorial. 1994. pág. 78 . 
edificación fue concebida para ser un Museo que albergue las colecciones de arte contemporáneo, tanto en lo referente a su exhibición como a su conservación (depósitos). Acerca de estos, Gloria Zea, su directora, comenta: "La primera exposición fue precisamente una colectiva de pinturas y esculturas prometidas al MAMBO, queriéndose indicar con ello que ahora que existían unos depósitos adecuados para la conservación de obras de arte, uno de los principales énfasis en nuestro trabajo sería el de enriquecer el acervo del Museo" ${ }^{\text {. }}$.

La edificación del Museo tiene un carácter especial, tiene el sello Salmona: construcción de ladrillo a la vista, pasadizos en rampa, entradas y salidas de las salas poco convencionales, desplazamientos por escalera circular entre nivel y nivel, iluminación artificial e iluminación natural mediante grandes ventanales y claraboyas en la iluminación cenital de las salas. Esta edificación tuvo una remodelación interior: las paredes de ladrillo y concreto fueron cubiertas por paredes sobrepuestas de yeso convirtiéndolo en un Cubo blanco sobre el cual cualquier obra, montaje, etc., tuviera más realce y no desentonara con el fondo de ladrillos. El Cubo blanco es una disposición aséptica muy utilizada en galerías y museos de arte moderno. Se quiere con ella, que la obra de arte hable por sí misma sin distorsiones del entorno (colores del fondo, vanos, mobiliarios o cualquier otro tipo de decoración). El interior del MAMBO, aunque fue revestido de blanco, no acalla el protagonismo de la arquitectura y las obras expuestas como accesorio. El diseño de Salmona sobresale.

\section{ORGANIGRAMA DE FUNCIONES}

El MAMBO es una fundación autónoma de carácter privado y cuenta con una Junta Directiva y Miembros Honorarios.

La administración del Museo cuenta con una Directora y un Gerente Administrativo. Los Departamentos en que se divide son: Contabilidad, Desarrollo y Mercadeo, Prensa, Curaduría, Educación, Conservación y Registro; Cine y Fotografía.

\section{CONSIDERACIONES}

El MAMBO es una institución importante porque guarda una parte significativa del patrimonio cultural de la nación colombiana: el Patrimonio Artístico Contemporáneo. Sin embargo hay mucho por hacer: "Una de nuestras misiones es mostrar el enorme talento artístico que hay en Colombia, lo que hace que no seamos un museo muerto; pero al mismo tiempo es injusto que no podamos mostrar la colección de arte más importante del país de la manera apropiada, por falta de espacio", insiste su directora. Efectivamente, no existe una exposición permanente que muestre el patrimonio artístico colombiano y cumple ahora la función de una galería con sus muestras temporales que abarcan la totalidad del espacio para exponer.

ZEA, Gloria.... pág. 41 
Es notable que el Museo se haya propuesto explícitamente hacer una Escuela de Guías. Un guía es un comunicador cordial, un investigador curioso y apasionado en la apreciación y en la historia del arte, y por todo esto es el puente de comunicación que acerca los nuevos lenguajes plásticos al público (abstracción, minimalismo, conceptualismo, etc.) y sugiere, pero nunca impone una lectura al espectador.

A pesar de hallarse dentro del Organigrama el Departamento de Conservación y Registro, no se tiene mucha información al respecto. Una colección de arte moderno exige mucho cuidado por la fragilidad en sus materiales, la complejidad de estructuras y técnicas diferentes que materializan una misma obra, así como formatos difíciles de conservar, etc.; consideraciones que deben estar muy presentes en los museos de arte contemporáneo.

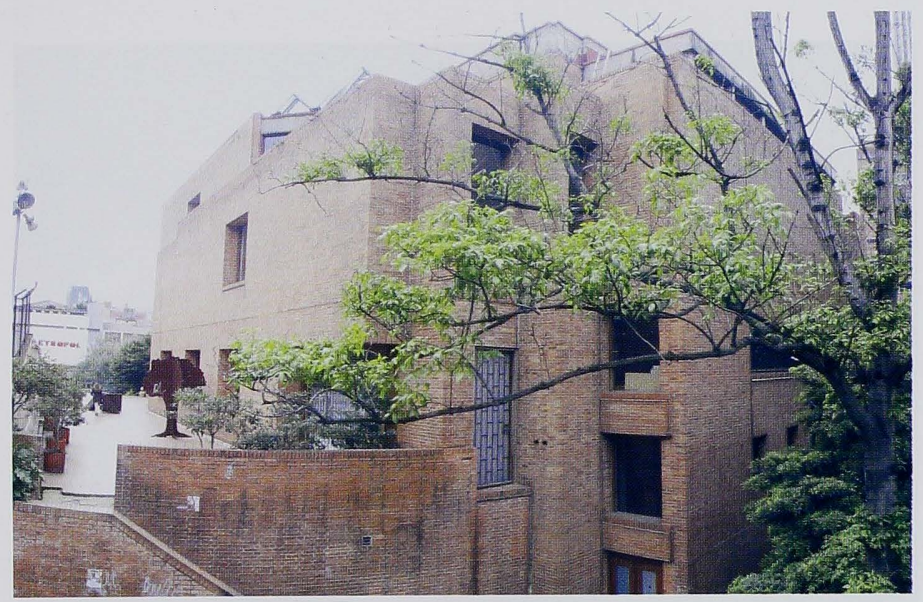

Finalmente vale la pena abrir la discusión en torno al significado del museo desde una perspectiva filosófica, como lo hace el destacado filósofo colombiano Jaime Rubio ${ }^{3}$. Una discusión en ese sentido es especialmente pertinente cuado se trata de un museo de arte contemporáneo. Tradicionalmente se define al museo como "el lugar de una ciudad donde una sociedad almacena los artefactos que ha seleccionado porque constituyen la trama de su memoria material: constituyen la colección que el museo preserva, restaura y aumenta". Sin embargo, el museo puede ser entendido como un lugar filosófico (Francois Dagones): la situación, la arquitectura, la distribución de las salas, las colecciones expresan una ideología. Los museos responden a una búsqueda, quizás de nosotros mismos; en ellos queremos exorcizar la angustia de lo irreversible y la tensión entre un futuro imprevisible y un pasado dejado atrás. El museo realiza un 'trabajo', según Lyotard, acota Rubio : “el trabajo de poner y/o transformar en monumento cualquier cosa. Trabajo que se sitúa entre el

RUBIO ANGULO, Jaime. El museo: memoria y virtualidad. Bogotá: UNAL, Colecciónsincondición, 2. 2005 Idem, pág. 6. 
olvido y la memoria, entre el olvido evasivo y el enigma, entre el olvido liberador y la supervivencia no sólo de objetos reales sino virtuales, inconscientes, creados allí mismos en la experiencia de las visitas de los diferentes públicos. El museo es también virtual, no en el sentido de que conserve ahora imágenes numéricas, cyber art, o su construcción arquitectónica involucre estos adelantos, sino en el sentido de que el museo desenraíza, nos obliga a abandonar los adornos del pensamiento, a desdogmatizarlo todo; nos abre a la novedad inconclusa en la que no se sabe dónde queda el objeto "real". Hay un peligro que acecha al museo, dice Malraux, citado por Rubio ${ }^{5}$, el peligro de olvidar el origen y olvidar sus virtualidades. Si esto sucede: "El museo resulta ser museo, no de color, sino de cuadros; no de escultura, sino de estatuas". 